\title{
Prevalence of Comorbidities in Patients with Chronic Obstructive Pulmonary Disease
}

\author{
Mario Cazzola a, bermano Bettoncelli ${ }^{c}$ Emiliano Sessa ${ }^{c}$ Claudio Cricelli ${ }^{c}$ \\ Gianluca Biscione $^{\mathrm{d}}$ \\ aDivision of Respiratory Diseases, Department of Internal Medicine, University of Rome Tor Vergata, Rome, \\ bPulmonary Rehabilitation Group, San Raffaele Pisana Hospital, Rome, 'Health Search Institute, Italian College of \\ General Practitioners, Florence, and d Division of Pulmonary Rehabilitation, San Raffaele Hospital, Velletri, Italy
}

\section{Key Words}

Cardiovascular events $\cdot$ Chronic obstructive pulmonary

disease $\cdot$ Depression $\cdot$ Osteoporosis

\begin{abstract}
Background: Chronic obstructive pulmonary disease (COPD) is associated with many comorbidities, but the percentage of COPD patients who develop comorbidities has not been clearly defined. Objectives: We aimed to examine the relationship between COPD and comorbidities using information obtained from the Health Search Database (HSD) owned by the Italian College of General Practitioners (SIMG), which stores information on about $1.5 \%$ of the total Italian population served by general practitioners. Methods: We conducted a population-based retrospective study using information obtained from the HSD. The software system used codes all the diagnostic records using the 9th Revision of the International Classification of Diseases. Results: Compared to the non-COPD people, COPD patients were at increased risk for cardiovascular events [ischemic heart disease $(6.9 \%$ in the general population vs. $13.6 \%$ in COPD patients), cardiac arrhythmia $(6.6 \%$ in the general population vs. $15.9 \%$ in COPD patients), heart failure (2.0\% in the general population vs. $7.9 \%$ in COPD patients), and other forms of heart disease ( $10.7 \%$ in the general population vs. $23.1 \%$ in COPD patients);
\end{abstract}

with a higher impact of COPD in the elderly]; non-psychotic mental disorders, including depressive disorders $(29.1 \%$ in the general population vs. $41.6 \%$ in COPD patients; with a higher impact of COPD on women aged $<75$ years); diabetes mellitus $(10.5 \%$ in the general population vs. $18.7 \%$ in COPD patients); osteoporosis (10.8\% in the general population vs. $14.8 \%$ in COPD patients), with a higher impact of COPD on women aged $<75$ years, and malignant pulmonary neoplasms $(0.4 \%$ in the general population vs. $1.9 \%$ in COPD patients). Conclusions: Our results indicate that COPD is a risk factor for these comorbid conditions.

Copyright $\odot 2010$ S. Karger AG, Basel

\section{Introduction}

The emerging recognition that chronic obstructive pulmonary disease (COPD) is a complex disorder, characterized by systemic inflammation in addition to local pulmonary inflammation, which might adversely affect various extrapulmonary organs, e.g. blood vessels and the heart, emphasizes the need for more information [1]. In effect, a large body of evidence now suggests the presence of a low-grade systemic inflammatory response in COPD $[2,3]$. COPD is, in fact, associated with increased levels of several proinflammatory cytokines such as TNF-

\section{KARGER}

Fax +4161306 1234

E-Mail karger@karger.ch

www.karger.com (c) 2010 S. Karger AG, Basel

$0025-7931 / 10 / 0802-0112 \$ 26.00 / 0$

Accessible online at:

www.karger.com/res
Mario Cazzola

Cattedra di Malattie Respiratorie, Dipartimento di Medicina Interna

Università di Roma Tor Vergata

Via Montpellier 1, IT-00133 Roma (Italy)

Tel./Fax +39062090 3615, E-Mail mario.cazzola@uniroma2.it 
$\alpha$ and IL-6, and C-reactive protein, an acute-phase protein induced by systemic increases in IL- 6 , in the systemic circulation of COPD patients [4-6].

Systemic inflammation has been implicated in the pathogenesis of the majority (if not all) of the systemic effects of COPD described to date, including weight loss, skeletal muscle dysfunction, cardiovascular disease, depression, and osteoporosis [7-9].

Other chronic conditions, such as chronic heart failure, obesity, or diabetes, and even the normal process of aging, also appear to be associated with a similar lowgrade systemic inflammatory process [10-12]. Intriguingly, a recent provocative viewpoint written by Fabbri and Rabe [13] has proposed a more comprehensive approach to diagnosis, assessment of severity, and management of COPD and its comorbidities. In patients who develop clinical and functional COPD disturbances, the diagnostic approach to COPD should be linked to the search for signs of a more general disorder, to be named chronic systemic inflammatory syndrome.

Unfortunately, however, the percentage of COPD patients who develop comorbidities has not been clearly defined. General practice databases offer a rich resource for epidemiological research [14]. They are population based and can quickly produce large samples of patients and matched controls. The databases can be used to conduct cross-sectional, case-control, and cohort studies rapidly and efficiently, and they provide good information on demographic characteristics, treatment, and diagnoses [14].

The aim of our study was, therefore, to examine the relationship between COPD and comorbidities using information obtained from the Health Search Database (HSD) owned by the Italian College of General Practitioners (SIMG), which stores information on about $1.5 \%$ of the total Italian population served by general practitioners (GPs). For the purposes of this paper, we use as a definition of comorbidity 'the presence of one or more distinct disorders (or diseases) in addition to COPD, regardless of whether the comorbid conditions are or are not directly related to, or caused by COPD, and irrespective of whether they are or are not part of the spectrum of the natural history of COPD' that has been proposed by Rodríguez-Roisin and Soriano [15]. Implicit in the approach to the definition of comorbidity is the assumption that the coexisting disease state is pathophysiologically related to the index disease or represents a disease-specific complication, although this only accounts for part of the comorbid conditions [16].

\section{Patients and Methods}

\section{Collection of Information}

We conducted a population-based retrospective study using information obtained from the HSD. The HSD contains patient demographic details, medical records (e.g. diagnoses, tests, test results, and hospitalization data), drug history, and drug prevention records. The software system used codes all the diagnostic records utilizing the International Classification of Diseases (9th revision: ICD-9) [17]. The participating GPs use the same software to record data during their daily practice, and they agree to send periodically complete, but anonymous, records of their patients to the HSD. A unique patient code links demographic and prescription information, clinical events and diagnoses, hospital admission, and cause of death. It is well known that before using any data resource, particularly one that is based on computer records, it is necessary to determine the quality and completeness of the available information. Therefore, data are subject to a range of quality checks. Any variations within agreed ranges are investigated and submitted to each participating GP. Physicians who fail to meet standard quality criteria are not considered for epidemiological studies [14].

For this study, 418 GPs were selected to be representatives of the whole Italian population and also because they ensured the required data quality.

Since the study was a retrospective analysis of data already available in the HSD, and confidentiality of patients was in no way violated, local rules do not request approval by an ethics committee.

\section{Ascertainment of COPD and Comorbidities}

Cases of COPD were identified on the basis of the ICD-9 code (491, 492, and 496). Always using the ICD-9 code, we regarded as chronic specific comorbidities cases of ischemic heart disease (410-414), diseases of the pulmonary circulation (415-417), other forms of heart disease (420-429), cardiac arrhythmia (427), heart failure (428), metabolic syndrome (277.7), diabetes mellitus (250), osteoporosis (733.0), neurotic disorders, personality disorders and other non-psychotic mental disorders (300-316), depressive disorders not elsewhere classified (311), and malignant neoplasms of the trachea, bronchus, and lung (162).

\section{Results}

We identified a population of 341,329 individuals $(155,970$ men and 185,359 women) aged $\geq 45$ years and registered in the HSD at the end of December 2006. Only subjects aged 45 and older were examined because of the low prevalence of COPD among younger patients.

The overall prevalence of COPD was $4.4 \%$. It was greater in men (5.8\%) than in women (3.2\%), and increased with age for both men and women (table 1).

Overall, $31.1 \%$ of the study population was identified with a recorded code for non-psychotic mental disorders, including depressive disorders not elsewhere classified, 
Table 1. Distribution of the population examined and prevalence of COPD according to age groups

\begin{tabular}{lllllll}
\hline Age group & $\begin{array}{l}\text { Women } \\
\mathrm{n}\end{array}$ & $\begin{array}{l}\text { Men } \\
\mathrm{n}\end{array}$ & $\begin{array}{l}\text { Total } \\
\mathrm{n}\end{array}$ & $\begin{array}{l}\text { Women with } \\
\text { COPD, \% }\end{array}$ & $\begin{array}{l}\text { Men with } \\
\text { COPD, \% }\end{array}$ & $\begin{array}{l}\text { Subjects with } \\
\text { COPD, \% }\end{array}$ \\
\hline 45-54 years & 50,570 & 49,085 & 99,655 & 1.1 & 1.5 & 1.3 \\
55-64 years & 45,400 & 43,176 & 88,576 & 2.2 & 3.9 & 3.0 \\
65-74 years & 40,920 & 35,008 & 75,928 & 3.9 & 8.4 & 6.0 \\
75-84 years & 33,261 & 21,907 & 55,168 & 5.6 & 13.1 & 8.6 \\
$\begin{array}{l}\text { 85 years } \\
\text { Total }\end{array}$ & 15,208 & 6,794 & 22,002 & 5.7 & 12.8 & 7.9 \\
\hline
\end{tabular}

Table 2. Patients with and without COPD who reported other selected chronic conditions by age and gender (\% of the population examined)

\begin{tabular}{|c|c|c|c|c|c|c|}
\hline \multirow[t]{2}{*}{ Comorbidity } & \multicolumn{3}{|c|}{ COPD absent } & \multicolumn{3}{|c|}{ COPD present } \\
\hline & total & men & women & total & men & women \\
\hline Ischemic heart disease & 6.6 & 8.4 & 5.1 & 15.9 & 17.5 & 13.5 \\
\hline Diseases of the pulmonary circulation & 0.4 & 0.4 & 0.5 & 2.1 & 2.1 & 2.2 \\
\hline Cardiac arrhythmia & 6.9 & 6.8 & 7.0 & 13.6 & 13.5 & 13.6 \\
\hline Heart failure & 2.0 & 2.0 & 2.0 & 7.9 & 7.8 & 7.9 \\
\hline Other forms of heart disease & 10.7 & 10.6 & 10.8 & 23.1 & 22.9 & 23.4 \\
\hline Metabolic syndrome & 0.4 & 0.4 & 0.3 & 0.6 & 0.7 & 0.6 \\
\hline Diabetes mellitus & 10.5 & 11.8 & 9.4 & 18.7 & 19.4 & 17.6 \\
\hline Osteoporosis & 10.8 & 1.7 & 18.4 & 14.8 & 4.6 & 30.5 \\
\hline $\begin{array}{l}\text { Neurotic disorders, personality disorders and other } \\
\text { non-psychotic mental disorders }\end{array}$ & 258 & 20.4 & 30.4 & 342 & 30.1 & 40.6 \\
\hline Depressive disorders not elsewhere classified & 5.3 & 3.4 & 5.3 & 7.4 & $\begin{array}{r}30.1 \\
5.5\end{array}$ & 10.3 \\
\hline Malignant neoplasms of the trachea, bronchus, and lung & 0.4 & 0.7 & 0.2 & 1.9 & 2.7 & 0.6 \\
\hline
\end{tabular}

26.6\% with a code for any form of heart disease (ischemic heart disease, diseases of the pulmonary circulation, other forms of heart disease, cardiac arrhythmia, and heart failure), $10.8 \%$ with a code for osteoporosis, $10.5 \%$ with a code for diabetes mellitus, $0.4 \%$ with a code for a malignant neoplasm of the trachea, bronchus, and lung, and $0.4 \%$ with a code for dysmetabolic syndrome (table 2 ). The distribution of age and sex was different among the different diagnostic code groups (table 2; fig. 1, 2). Of those patients identified with a record of osteoporosis, non-psychotic mental disorder or depressive disorder, the majority were women, whereas the majority of those with a record of ischemic heart disease, diabetes mellitus, and malignant pulmonary neoplasms were men. No important gender difference was seen in the other diagnostic code groups. We also found that the majority of patients with a code for any form of heart disease was disproportionately old, whereas the distribution of age among the non-psychotic mental disorder code group was more homogeneous. Similarly, the distribution of age among the other diagnostic code groups was rather homogeneous, although we have observed a trend to increase with age (table 2).

The presence of COPD increased the prevalence of cardiovascular events [ischemic heart disease $(6.9 \%$ in the general population vs. $13.6 \%$ in COPD patients), cardiac arrhythmia (6.6\% in the general population vs. $15.9 \%$ in COPD patients), heart failure (2.0\% in the general population vs. $7.9 \%$ in COPD patients), and other forms of heart disease (10.7\% in the general population vs. $23.1 \%$ in COPD patients)] being irrespective of sex but not of age (table 2; fig. 1).

The prevalence of metabolic syndrome did not increase because of the presence of COPD $(0.6 \%)$ that, in any case, influenced the prevalence of diabetes mellitus (18.7\%; table 2). Moreover, women with COPD seemed to be at high risk to develop osteoporosis [10.8\% (women $18.4 \%$ and men $1.7 \%$ ) in the general population vs. $14.8 \%$ 


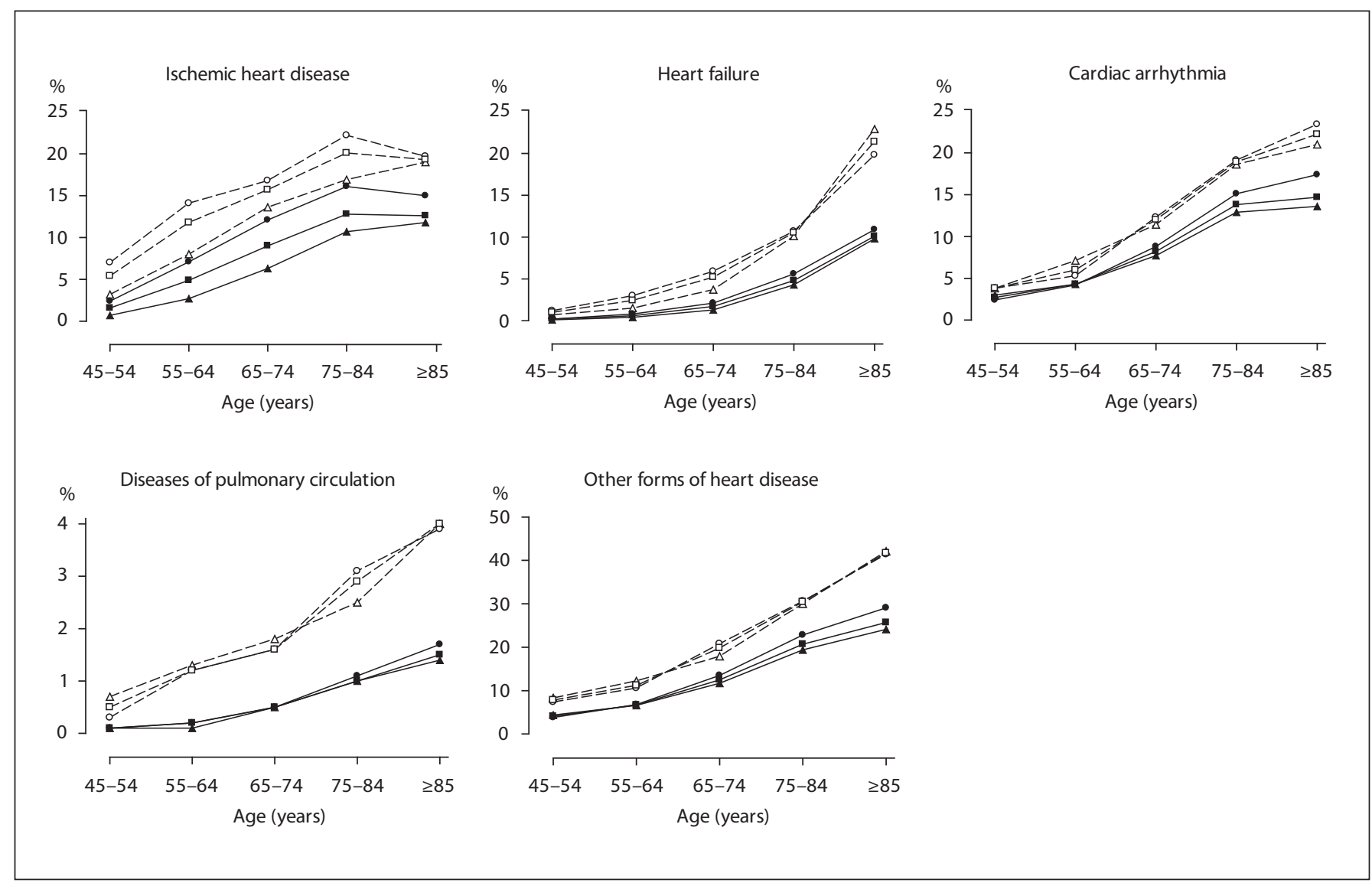

Fig. 1. People with $(\square \bigcirc \triangle$ ) and without COPD ( $\square \mathbf{\Delta}$ ) who reported cardiovascular comorbidities by age group and gender (\% of the examined population). $\mathbf{\square} \square=$ Total; $\bigcirc=$ men; $\Delta \triangle$ = women.

(women $30.5 \%$ and men $4.6 \%$ ) in COPD patients; table 2], although there was a decrease in the prevalence of osteoporosis in women aged $>75$ years regardless of the presence of COPD (fig. 2).

Compared to the non-COPD individuals, COPD patients were at increased risk for non-psychotic mental disorders, including depressive disorders not elsewhere classified (41.6\%; table 2). It must be mentioned that the impact of COPD on depressive disorders was mainly observed in women and became significant in those aged $\geq 55$ years although in those aged $\geq 75$ years the impact seemed to become less important (fig. 2).

Obviously, the presence of COPD increased the prevalence of malignant neoplasms of the trachea, bronchus, and lung $(0.4 \%$ in the general population vs. $1.9 \%$ in COPD patients; table 2; fig. 2).

\section{Discussion}

The results of our study, a retrospective analysis of a really large population, confirm that COPD is associated with several comorbidities. Another study in the past examined a general practice database, but with a different, more limited approach [18]. Patient data from the UK General Practice Research Database were analyzed to quantify baseline rates of comorbidities in 2,699 patients with COPD ( $46 \%$ were current smokers) compared with age-, sex-, practice-, and time-matched controls (21\% were current smokers). Angina, cataracts, and osteoporosis, all had a frequency $>1 \%$ within the 1 st year after COPD diagnosis. Furthermore, compared with controls, COPD patients had a significantly increased risk of comorbidities and other medical events. The authors concluded that COPD is associated with various comorbidities, particularly those related to cardiovascular-, bone- 


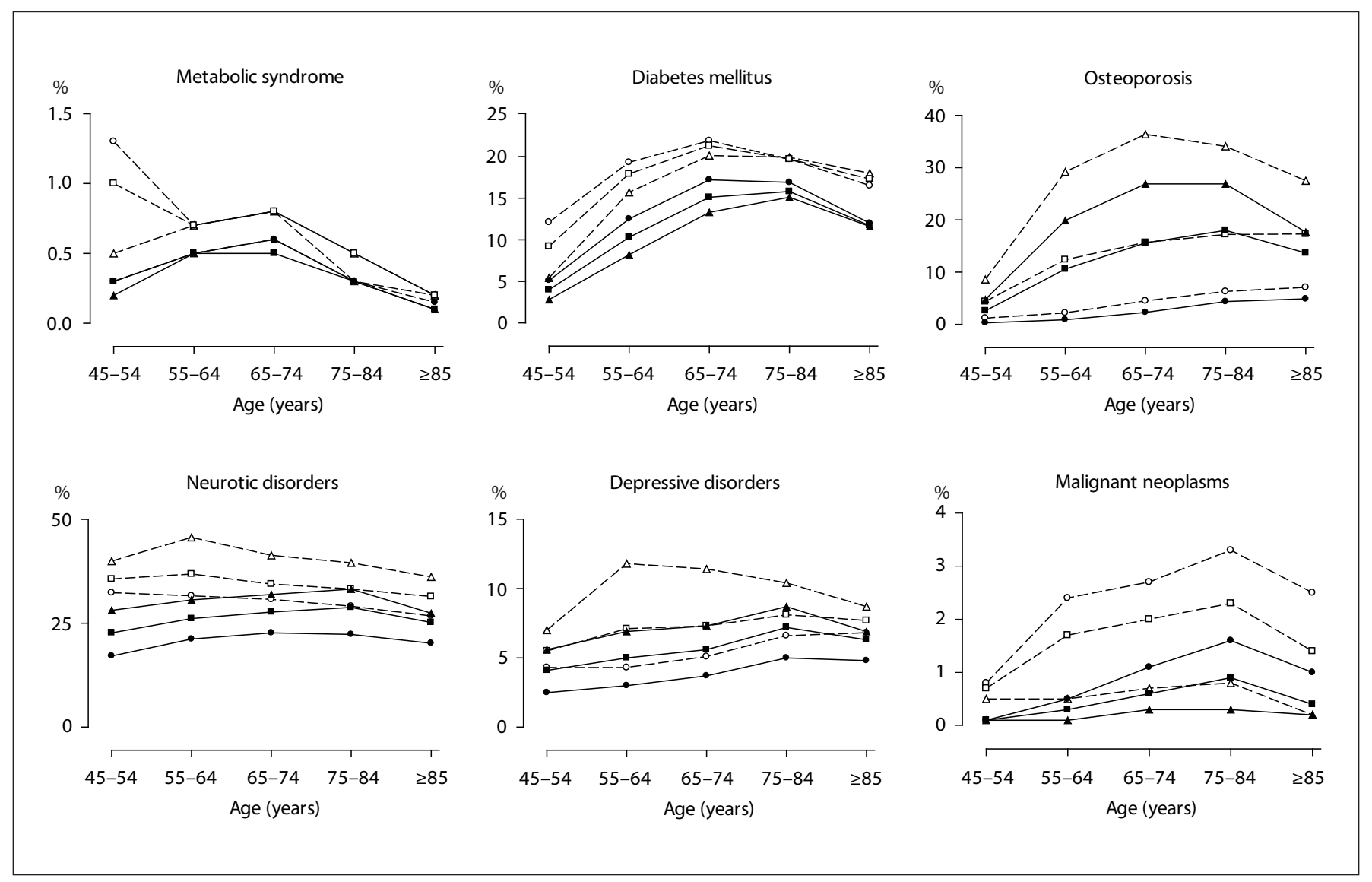

Fig. 2. People with $(\square \bigcirc \triangle$ ) and without $\operatorname{COPD}(\mathbf{\square} \mathbf{\Delta})$ who reported other selected comorbidities by age group and gender (\% of the examined population). $\square \square=$ Total; $\bigcirc=$ men; $\Delta \triangle$ = women.

and other smoking-related conditions, which previously had not been systematically documented.

The primary finding of this study is that patients with a history of COPD have a higher risk of suffering heart disease. This was not an unexpected finding because it is recognized that patients with impaired pulmonary function are at elevated risk of cardiovascular disease. Hole et al. [19] stratified a survey of 15,411 persons aged $45-64$ years into five groups, according to $\mathrm{FEV}_{1}$. After adjusting for risk factors, e.g. smoking, they found a significant inverse relationship between $\mathrm{FEV}_{1}$ and death due to ischemic heart disease and stroke. In a cross-sectional study of patients aged $>50$ years, Sin and Man [20] found that patients with severe airflow obstruction were 2.1 times more likely than controls to have electrocardiographic evidence of probable prior myocardial infarction. Also, using health care databases maintained by the government of Saskatchewan, Canada, Curkendall et al. [21] found that the prevalence of all cardiovascular diseases was higher in the COPD group than in the comparison group. After adjusting for cardiovascular risks, odd ratios of prevalence were: arrhythmia 1.76, angina 1.61, acute myocardial infarction 1.61, congestive heart failure 3.84, stroke 1.11, and pulmonary embolism 5.46.

The mechanisms by which the pulmonary changes induced by COPD can lead to these cardiovascular events are not clear. Cigarette smoking is a common risk factor of both diseases, but several pieces of evidence established that the association between COPD and cardiovascular disease remains independent of established risk factors [22]. It is likely that alterations in vascular structure are involved, including atherosclerosis and loss of large-artery elasticity. A potential factor is increased arterial stiffness, which is partly determined by vascular calcifications [23] and is related to chronic systemic inflammation [24]. It has been suggested that the inflam- 
matory process in the airways may spread to the systemic circulation, promoting a state of persistent low-grade systemic inflammation, which then in concert with traditional risk factors, such as hypertension and hypercholesterolemia, acts to foster plaque formation and rupture in susceptible individuals with COPD [25]. It is remarkable to observe the similarities of cardiac inflammation with lung inflammation. For example, ischemic heart disease is characterized by atherosclerosis of coronary arteries. In these vessels, there is endothelial dysfunction and an inflammatory process in the atheroma plaque with presence of macrophages, $\mathrm{T}$ cells, and increased proinflammatory cytokines and C-reactive protein [26]. However, it remains unclear whether systemic inflammation is a cause of cardiovascular disease, or merely a marker [27]. In any case, over the past 5 years, several other plausible explanations, such as increased oxidative stress, neurohumoral disturbances, and increased thrombotic tendency, have been provided [28]. All are very intriguing, but none is really definite.

A factor potentially linking COPD with the cardiovascular risk is the increased occurrence of osteoporosis [29], which in individuals without COPD is associated with atherosclerosis and arterial calcification [30, 31], although data from the Women's Health Initiative in the USA [32] have suggested that diabetes mellitus and depression can also be considered as increasing fracture risk. Because proinflammatory cytokines can significantly alter bone metabolism, excessive osteoporosis in relation to age could be considered a systemic effect of COPD [1]. However, Bolton et al. [29] and Sabit et al. [33] did not find a relationship between inflammatory mediators and the presence of bone disease in COPD patients and in healthy subjects in two separate studies. Consequently, further research is required to evaluate the possible relationships between systemic inflammation and bone loss in COPD. In any case, there are numerous risk factors that contribute to the pathophysiology of osteoporosis seen in COPD patients [34]. These risk factors include smoking, vitamin D deficiency, low body mass index, hypogonadism, and decreased mobility as the disease progresses. In addition to these risk factors, in many patients with COPD, glucocorticoid use is thought to be a contributing factor in the development of osteoporosis, but osteoporosis has also been reported in COPD patients who have no history of corticosteroid use [34]. Our finding provides evidence that the increase in osteoporosis in COPD patients is noteworthy, but it seems to clearly prevail in women and this is in contrast with the recent documentation that osteoporosis is highly prevalent in severe COPD and affects males to a similar degree as females [35]. Also, Jørgensen et al. [36] found a higher prevalence of osteoporosis in women than in men with COPD. They suggested that this is partially because women are less resistant to the harmful side effects of smoking than men, live longer, and therefore reach an older age with their lung disease. This hypothesis is suggestive, but we must mention that in our population we have noticed a decrease in the prevalence of osteoporosis in women aged $>75$ years regardless of the presence of COPD.

What seems to be strange is the fact that our data suggest that COPD does not increase the risk of the metabolic syndrome, whereas it is well known that the metabolic syndrome is an important risk factor for cardiovascular disease prevalence and mortality, as well as all-cause mortality [37]. The metabolic syndrome is a complex disorder recognized clinically by the findings of abdominal obesity, atherogenic dyslipidemia, elevated blood pressure, high blood glucose and/or insulin resistance [38]. Surprisingly, in our COPD patients, we have observed an increased prevalence of cardiovascular diseases and diabetes but a very low prevalence of the metabolic syndrome. Apparently, this finding would suggest that COPD per se, but not the metabolic syndrome, is a real risk factor for cardiovascular diseases and diabetes. Nonetheless, it must be mentioned that although the prevalence of the metabolic syndrome varies among studies, mostly because of different definitions of the syndrome, it has been suggested that the metabolic syndrome has a high prevalence in family practice populations, but some argue that combining risk factors and calling the combination a syndrome is of limited use [39]. This could be the reason for the apparent low prevalence of the metabolic syndrome recorded in our survey.

Anxiety and depression are very common comorbidities in COPD. They often occur concomitantly in patients with COPD [40]. Factors such as cigarette smoke exposure, increased incidences of dyspnea, physical inactivity and social isolation, chronic hypoxia, and long-term oxygen therapy may contribute to these psychological disorders in COPD [41]. In stable COPD, the prevalence of clinical depression ranges between 10 and $42 \%$, while that of anxiety ranges between 10 and 19\% [42]. Our data support these figures.

Our results are interesting because they come from a large, validated, population-based database that illustrates what can be observed in real life and can be considered representative of the general population. However, we must admit that the present study has important 
limitations, many of which are common to retrospective database analyses. These limitations might be associated mainly with bias towards the selection of more highly motivated, or better organized, practices. Consequently, our findings might likely be an overestimate of the general picture on the one hand. Nonetheless, on the other hand, it is well known that patients vary in their use of health care and it is accepted that a significant proportion of patients who are ill may not consult their doctor and this can lead to underestimation of the problem. Moreover, we must emphasize that HSD data relate to those diagnoses for which a relevant medication is prescribed. Thus, for example, a diabetic patient who is controlled with diet therapy will not be detected. This limitation may underestimate the true prevalence of the disease, but it ensures that the condition is currently active, and the diagnosis is severe enough to require pharmacotherapy.

We must also highlight that there may have been misclassification when our GPs have used specific diagnostic categories and this likely because there are no standardized methods of applying diagnostic labels in general practice. GPs are faced with an array of alternative codes for the same or similar conditions and, in effect, practicing physicians have little faith in the accuracy of the ICD9 diagnoses entered for prescription purposes and this can question the real value of diagnoses in the HSD, including that of COPD. It is well known that errors in the diagnosis and proper classification of COPD patients with respiratory symptoms in the primary healthcare are frequent, and therefore all patients suspected to have COPD should undergo spirometry [43]. The results of a recent survey, which has used the HSD and documented COPD was established without spirometry [44], might be considered an example of the risk of possible COPD misdiagnoses. It is also critical that the study that SIMG carried out to investigate the degree of control of physiciandiagnosed asthma and COPD in Italy between April 2002 and May 2002, using data from questionnaires filled in by the GPs [45], documented that in most COPD patients cases, the physician used only symptom frequency as a measure of severity and, furthermore, in $8.9 \%$ of cases the physician used only the level of airflow obstruction as ic disease have more than one relevant diagnosis and the diagnosis recorded on the motherboard for any particu-

lar visit may not be the primary reason for the visit. Furthermore, many physicians informally report paying little attention to the accuracy of the diagnosis recorded, relying instead on codes committed to memory from frequent use [46].

Nonetheless, we must highlight that comparative analyses have demonstrated the validity of the information gathered in the HSD [47]. Therefore, we believe that the prevalence of comorbidities in our COPD patients seems to be realistic because the use of a populationbased general practice database allows studying a real-life clinical setting, although we must acknowledge that we have been unable to examine the relationship between differing levels of COPD severity and comorbid conditions as data on spirometry were not collected.

Moreover, we must also admit that this is a cross-sectional study and, consequently, the temporal relationship between clinically relevant comorbidities and COPD is unknown. Therefore, we are unable to understand whether COPD is only a component of the chronic systemic inflammatory syndrome as suggested by Fabbri and Rabe [13], or the inflammation in the lung is spread to the systemic circulation to produce systemic effects and, consequently, comorbidities. However, the prevalence rates of different comorbidities observed while analyzing the HSD suggest that the second hypothesis seems to be more likely, although we cannot exclude the possibility of a concomitant disease that causally appeared in a patient suffering from COPD. that in almost two thirds of patients the diagnosis of $(66.2 \%)$ the level of severity was defined according to symptom frequency together with the level of airflow obstruction measured by spirometry. However, in $24.9 \%$ of measured by spirometry.

A third critical issue is that most patients with chron-

References
Cazzola/Bettoncelli/Sessa/Cricelli/ Biscione
1 Agusti A: Chronic obstructive pulmonary disease: a systemic disease. Proc Am Thorac Soc 2006;3:478-481.

2 Agusti AG, Noguera A, Sauleda J, Sala E, Pons J, Busquets X: Systemic effects of chronic obstructive pulmonary disease. Eur Respir J 2003;21:347-360.

3 Wouters EF, Creutzberg EC, Schols AM: Systemic effects in COPD. Chest 2002;121: 127S-130S

4 de Torres JP, Cordoba-Lanus E, López-Aguilar C, Muros de Fuentes M, Montejo de Garcini A, Aguirre-Jaime A, Celli BR, Casanova C: C-reactive protein levels and clinically important predictive outcomes in stable COPD patients. Eur Respir J 2006;27:902907.

$\checkmark 5$ Piehl-Aulin K, Jones I, Lindvall B, Magnuson A, Abdel-Halim SM: Increased serum inflammatory markers in the absence of clinical and skeletal muscle inflammation in patients with chronic obstructive pulmonary disease. Respiration 2009;78:191-196. 
6 Murphy CA, Blyth KG, Chaudhuri R, Lafferty J, Hothersall E, Steedman T, McSharry C, Dargie HJ, Thomson NC: Assessment of the presence of occult myocardial infarction in chronic obstructive pulmonary disease using contrast-enhanced cardiac magnetic resonance imaging. Respiration 2009;78: 263-269.

7 Gan WQ, Man SF, Senthilselvan A, Sin DD: Association between chronic obstructive pulmonary disease and systemic inflammation: a systematic review and a meta-analysis. Thorax 2004;59:574-580.

-8 Agustí A: Systemic effects of chronic obstructive pulmonary disease: what we know and what we don't know (but should). Proc Am Thorac Soc 2007;4:522-525.

-9 van Eeden SF, Sin DD: Chronic obstructive pulmonary disease: a chronic systemic inflammatory disease. Respiration 2008; 75 : 224-238.

10 De Martinis M, Franceschi C, Monti D, Ginaldi L: Inflamm-ageing and lifelong antigenic load as major determinants of ageing rate and longevity. FEBS Lett 2005;579: 2035-2039.

-11 Sevenoaks MJ, Stockley RA: Chronic obstructive pulmonary disease, inflammation and co-morbidity - a common inflammatory phenotype? Respir Res 2006;7:70.

$\checkmark 12$ Fabbri LM, Luppi F, Beghé B, Rabe KF: Complex chronic comorbidities of COPD. Eur Respir J 2008;31:204-212.

13 Fabbri LM, Rabe KF: From COPD to chronic systemic inflammatory syndrome? Lancet 2007;370:797-799.

-14 Lawrenson R, Williams T, Farmer R: Clinical information for research: the use of general practice databases. J Public Health Med 1999;21:299-304.

15 Rodríguez-Roisin R, Soriano JB: Chronic obstructive pulmonary disease with lung cancer and/or cardiovascular disease. Proc Am Thorac Soc 2008;5:842-847.

16 van Weel C, Schellevis FG: Comorbidity and guidelines: conflicting interests. Lancet 2006:367:550-551.

17 World Health Organization: International Classification of Diseases. Manual of the International Statistical Classification of Diseases: Injuries and Causes of Deaths (9th revision). Geneva, World Health Organization, 1977.

18 Soriano JB, Visick GT, Muellerova H, Payvandi N, Hansell AL: Patterns of comorbidities in newly diagnosed COPD and asthma in the primary care. Chest 2005;128:20992107.

-19 Hole DJ, Watt GCM, Davey-Smith G, Hart CL, Gillis CR, Hawthorne VM: Impaired lung function and mortality risk in men and women: findings from the Renfrew and Paisley prospective population study. BMJ 1996; 313:711-715.

20 Sin DD, Man SF: Why are patients with chronic obstructive pulmonary disease at increased risk of cardiovascular diseases? The potential role of systemic inflammation in chronic obstructive pulmonary disease. Circulation 2003;107:1514-1519.

21 Curkendall SM, DeLuise C, Jones JK, Lanes S, Stang MR, Goehring E Jr, She D: Cardiovascular disease in patients with chronic obstructive pulmonary disease, Saskatchewan Canada cardiovascular disease in COPD patients. Ann Epidemiol 2006;16:63-70.

22 Deyo RA, Cherkin DC, Ciol MA: Adapting a clinical comorbidity index for use with ICD9-CM administrative databases. J Clin Epidemiol 1992;45:613-619.

23 Laurent S, Boutouyrie P, Lacolley P: Structural and genetic bases of arterial stiffness. Hypertension 2005;45:1050-1055.

24 Roman MJ, Devereux RB, Schwartz JE, Lockshin MD, Paget SA, Davis A, Crow MK, Sammaritano L, Levine DM, Shankar BA, Moeller E, Salmon JE: Arterial stiffness in chronic inflammatory diseases. Hypertension 2005;46:194-199.

25 Sin DD, Man SF: Chronic obstructive pulmonary disease: a novel risk factor for cardiovascular disease. Can J Physiol Pharmacol 2005;83:8-13.

26 Buffon A, Biasucci LM, Liuzzo G, D’Onofrio G, Crea F, Maseri A: Widespread coronary inflammation in unstable angina. $\mathrm{N}$ Engl $\mathrm{J}$ Med 2002;347:5-12.

27 Macnee W, Maclay J, McAllister D: Cardiovascular injury and repair in chronic obstructive pulmonary disease. Proc Am Thorac Soc 2008;5:824-833.

28 Tkác J, Man SFP, Sin DD: Systemic consequences of COPD. Ther Adv Respir Dis 2007; $1: 47-59$.

-29 Bolton CE, Ionescu AA, Shiels KM, Pettit RJ, Edwards PH, Stone MD, Nixon LS, Evans WD, Griffiths TL, Shale DJ: Associated loss of fat-free mass and bone mineral density in chronic obstructive pulmonary disease. Am J Respir Crit Care Med 2004;170:12861293.

30 Tanko LB, Bagger YZ, Christiansen C: Low bone mineral density in the hip as a marker of advanced atherosclerosis in elderly women. Calcif Tissue Int 2003;73:15-20.

-31 Schulz E, Arfai K, Liu X, Sayre J, Gilsanz V: Aortic calcification and the risk of osteoporosis and fractures. J Clin Endocrinol Metab 2004;89:4246-4253.

32 Cauley JA, Wu L, Wampler NS, Barnhart JM, Allison M, Chen Z, Jackson R, Robbins J: Clinical risk factors for fractures in multiethnic women: the Women's Health Initiative. J Bone Miner Res 2007;22:1816-1826.

- 33 Sabit R, Bolton CE, Edwards PH, Pettit RJ, Evans WD, McEniery CM, Wilkinson IB, Cockcroft JR, Shale DJ: Arterial stiffness and osteoporosis in chronic obstructive pulmonary disease. Am J Respir Crit Care Med 2007;175:1259-1265.

34 Biskobing DM: COPD and osteoporosis. Chest 2002;121:609-620.

35 Li L, Brennan KJ, Gaughan JP, Ciccolella DE, Kuzma AM, Criner GJ: African Americans and men with severe COPD have a high prevalence of osteoporosis. COPD 2008;5:291297.

-36 Jørgensen NR, Schwarz P, Holme I, Henriksen BM, Petersen LJ, Backer V: The prevalence of osteoporosis in patients with chronic obstructive pulmonary disease: a cross sectional study. Respir Med 2007;101:177185.

37 Lakka HM, Laaksonen DE, Lakka TA, Niskanen LK, Kumpusalo E, Tuomilehto J, Salonen JT: The metabolic syndrome and total and cardiovascular disease mortality in middle-aged men. JAMA 2002;288:27092716.

- 38 Grundy SM, Cleeman JI, Daniels SR, Donato KA, Eckel RH, Franklin BA, Gordon DJ, Krauss RM, Savage PJ, Smith SC Jr, Spertus JA, Costa F, American Heart Association, National Heart, Lung, and Blood Institute: Diagnosis and management of the metabolic syndrome. Circulation 2005;112:2735-2752.

-39 van den Hooven C, Ploemacher J, Godwin M: Metabolic syndrome in a family practice population: prevalence and clinical characteristics. Can Fam Physician 2006;52:982983.

40 Kunik ME, Roundy K, Veazey C, Souchek J, Richardson P, Wray NP, Stanley MA: Surprisingly high prevalence of anxiety and depression in chronic breathing disorders. Chest 2005;127:1205-1211.

41 Hill K, Geist R, Goldstein RS, Lacasse Y: Anxiety and depression in end-stage COPD. Eur Respir J 2008;31:667-677.

-42 Maurer J, Rebbapragada V, Borson S, Goldstein R, Kunik ME, Yohannes AM, Hanania NA: Anxiety and depression in COPD: current understanding, unanswered questions, and research needs. Chest 2008;134(4 suppl):43S-56S.

43 Sichletidis L, Chloros D, Spyratos D, Chatzidimitriou N, Chatziiliadis P, Protopappas N, Charalambidou O, Pelagidou D, Zarvalis E, Patakas D: The validity of the diagnosis of chronic obstructive pulmonary disease in general practice. Prim Care Respir J 2007; 16: 82-88.

44 Cazzola M, Bettoncelli G, Sessa E, Cricelli C: Primary care of the patient with chronic obstructive pulmonary disease in Italy. Respir Med 2009; 103:582-588.

45 Caramori G, Bettoncelli G, Carone M, Tosatto R, Di Blasi P, Pieretto A, Invernizzi G, Novelletto BF, Ciaccia A, Adcock IM, Papi A: Degree of control of physician-diagnosed asthma and COPD in Italy. Monaldi Arch Chest Dis 2007;67:15-22.

46 Katz A, Soodeen RA, Bogdanovic B, De Coster C, Chateau D: Can the quality of care in family practice be measured using administrative data? Health Serv Res 2006;41: 2238-2254

47 Filippi A, Bignamini AA, Sessa E, Samani F, Mazzaglia G: Secondary prevention of stroke in Italy: a cross-sectional survey in family practice. Stroke 2003;34:1010-1014. 